MEMÓRIA

\title{
O Tecpar e o Centro de Tecnologia Industrial Brasil-Japão
}

\author{
Carlos Fior \\ Instituto de Tecnologia do Paraná (Tecpar) \\ Mariano de Matos Macedo \\ Instituto Paranaense de Desenvolvimento Econômico e Social - Ipardes e Universidade Federal do Paraná (UFPR)
}

O objetivo dessas notas não é apresentar a história do Instituto de Tecnologia do Paraná (Tecpar), mas sim identificar, na trajetória da instituição, fatos ou momentos críticos que implicaram redefinições, expansão ou modificações qualitativas no seu escopo ou formas de atuação e que vieram a reafirmar a importância do Tecpar como um instituto de tecnologia diante das demandas específicas colocadas pelas transformações verificadas na economia e sociedade brasileira, em geral, e na paranaense, em particular.

Além disso, pretende-se destacar um desses fatos ou momentos, no sentido de oferecer uma contribuição adicional para a compreensão da importância estratégica dos institutos de tecnologia, no conjunto de instituições vinculadas à área da CT\&I.

Dado esse objetivo, será destacado, na memória do Tecpar, o Acordo de Cooperação Técnica entre o Governo do Paraná e a Província de Hyogo, no Japão, que contribuiu decisivamente para o fortalecimento das ações do Tecpar na prestação de serviços tecnológicos à indústria, por meio da criação do seu Centro de Tecnologia Industrial, acompanhando o desenvolvimento da Cidade Industrial de Curitiba CIC, no decorrer dos anos 1980.

Essa iniciativa foi de expressiva importância para viabilizar a instalação de um campus do Tecpar na própria CIC, com estruturas laboratoriais específicas para a 
prestação desse tipo de serviços, além de favorecer a disseminação interna de padrōes de garantia da qualidade, em geral.

De forma a caracterizar esse fato como um momento crítico na trajetória do Instituto, é importante situá-lo entre outros acontecimentos dessa natureza que marcaram sua história. ${ }^{1}$

Logicamente, o primeiro momento refere-se à origem do Instituto, que remonta a 1940, quando da criação do Laboratório de Análises e Pesquisas (LAP), no âmbito do Departamento de Agricultura, da Secretaria de Estado de Obras Públicas, Viação e Agricultura. Esse Laboratório foi instalado em um prédio construído no bairro atualmente denominado Juvevê, em região próxima ao centro de Curitiba.

Em fevereiro de 1941, por meio do Decreto-Lei no 11.008, com base no LAP, foi criado o Instituto de Biologia Agrícola e Animal (IBAA). Anexo a esse Decreto, o Regulamento do Instituto definiu as suas seguintes competências: estudar o solo do Estado, a fim de verificar a distribuição dos diversos tipos de terras e determinar suas possibilidades para as diversas culturas econômicas; preparar soros e produtos terapêuticos para tratamento e profilaxia das doenças dos animais domésticos; analisar os diversos produtos vegetais e estudar as possibilidades de seu aproveitamento industrial; estudar e orientar o combate às epifitias e epizootias e organizar campanha contra pragas que prejudicam a lavoura; analisar, em seus laboratórios, terras, adubos, água, fungicidas, inseticidas, parasiticidas, minérios e produtos agrícolas; estudar os produtos destinados à alimentação dos animais domésticos; proteger agricultores e criadores contra as fraudes e adulterações de produtos destinados à agricultura e pecuária; estudar e pesquisar a industrialização, transformação e aproveitamento dos produtos de origem animal, inclusive a aplicação da criologia para conservação de tais produtos; estudar a flora indígena e as plantas cultivadas no Estado do ponto de vista sistemático, ecológico, fisiológico e econômico; e estudar e determinar as plantas tóxicas aos animais, medicamentosas e outras que interessem à lavoura (BRAND; ROCHA, 1991, p. 29-30).

Além da realização de estudos e pesquisas, já em 1941, o Instituto apresentava a característica de aliar $\mathrm{P} \& \mathrm{D}$ e produção/comercialização, que vai permear sua história. Nesse ano, suas linhas de produção, em escala comercial, eram as seguintes: Uroiba, Sulfaniba, soro fisiológico, vacina contra garrotilho, vacina contra raiva, vacina contra o tifo aviário, pomadas, soro glicosado isotônico, óleo canforado, soro glicosado hipertônico, vermífugo para porcos e cães, preparado contra coriza

1 A análise realizada a seguir está baseada em Brand e Rocha (1991), Lunardi (1993) e Meartins (2006). 
e difteria das aves, vacina contra curso branco, vacina contra paratifo dos porcos, Oleiba "A", Oleiba "B", vermífugo para ruminantes, vermífugo para equinos, gluconato de cálcio, vacina contra aborto e vacina contra poliartrite de potros (BRAND; ROCHA, 1991, p. 32). ${ }^{2}$

Esse escopo de atuação é pertinente às demandas impostas pela extensa expansão da fronteira agropecuária brasileira e estadual, marcada pelo processo de ocupação do norte do Paraná, verificado com intensidade crescente a partir do início dos anos 1930. Esse processo - centrado em atividades rurais e urbanas vinculadas fundamentalmente à expansão da cafeicultura no Paraná - foi organizado, com o apoio do Estado, ${ }^{3}$ pela Companhia de Melhoramentos do Norte do Paraná, tendo por base o "loteamento" da região em pequenas e médias propriedades rurais. $\mathrm{O}$ indicador da expressiva intensidade desse processo pode ser dado pela evolução da participação da produção de café do Paraná no total nacional: $0,4 \%$ na safra de 1920/21; 2,1\% em 1930/31; 5,7\% em 1940/41; e 24\% em 1950/51. Pode-se também observar o intenso crescimento da população estadual nos anos 1940, de 1,24 milhão, no início da década, para 2,1 milhôes de habitantes, em 1950 (5,5\% a.a), verificado, em sua grande parte, no norte do Estado ${ }^{4}$.

Ainda nesse contexto, em 1941, o Instituto de Biologia Agrícola e Animal passou a ser denominado Instituto de Biologia e Pesquisas Tecnológicas (IBPT), com vistas à ampliação do escopo de suas linhas de atuação para a produção industrial. Algumas iniciativas vinculadas às restriçôes de abastecimento impostas pela II Guerra Mundial caracterizaram essa mudança, tais como a fiscalização do carvão vegetal destinado à produção de gasogênio e as análises de pirita do carvão para fins de produção de ácido sulfúrico, em decorrência da escassez de enxofre. Ainda na década de 1940, o Instituto destacou-se com outras atividades: criação do Serviço de Combate à Broca do Café (1943); pesquisas e difusão do uso de calcário mineral como corretivo para acidez de solos (calagem), em substituição ao proveniente dos sambaquis, visando o aumento da produtividade agrícola; instalação, em 1945, de um laboratório de produção de vacinas contra a peste suína, no município de Jacarezinho, no Norte Velho do Paraná, em cooperação com o Ministério da Agricultura; e avanço da suas

2 Em geral, esses produtos estão voltados para a sanidade de animais (bovinos, aves, suínos e cães).

3 Merece atenção o fato de que, na época, uma das mais importantes Secretarias de Estado se denominava "Secretaria de Obras Públicas, Viação e Agricultura".

4 Essas informações têm como fonte o Anuário Estatístico do Café, publicado pelo Instituto Brasileiro do Café e são apresentadas por Padis (2006, p. 170). 
vertentes de bioquímica (ensino e pesquisa) e de biologia animal (controle sanitário e antígenos), além da realização de pesquisas geológicas, cuja uma das principais referências corresponde aos estudos elaborados por Reinhard Maack. Merecem ser destacadas a transformação do Instituto em autarquia, em 1951, e a criação, por meio de lei, em 1955, do Fundo de Pesquisas do IBPT.

No início dos anos 1950, foi criada, no IBPT, a Divisão Experimental de Combustíveis voltada para pesquisas sobre o aproveitamento energético do xisto piro-betuminoso das reservas existentes no município paranaense de São Mateus do Sul e o das bacias carboníferas do nordeste do Estado. O acervo das pesquisas realizadas pelo Instituto sobre o xisto foi transferido para a Petrobrás, no final da década. No caso das bacias carboníferas, as pesquisas resultaram, em 1963, na instalação da Usina Termoelétrica de Figueira, vinculada à Companhia Paranaense de Energia (Copel). No início dos anos 1960, a escassez de energia constituía um dos principais gargalos da economia paranaense.

Segundo Brand e Rocha (1991, p. 41), nessa época, "o maior obstáculo ao desenvolvimento das pesquisas do Instituto no campo da tecnologia industrial seriam, porém, as reduzidas dimensōes do parque fabril paranaense, que se traduziam por uma baixa, quase inexistente demanda de apoio de serviços científicos” e tecnológicos. De certa forma, essa situação perdurou até o final dos anos 1960.

Um segundo momento crítico da trajetória do Instituto pode ser observado no início da década de 1970. A partir de 1971, o IBPT implantou a produção em grande escala da vacina antirrábica canina, em convênio com o Ministério da Saúde, visando atender à demanda da Campanha Nacional de Profilaxia da Raiva. A tecnologia de produção teve por base a adaptação local do método desenvolvido pelos pesquisadores chilenos Fluenzalida e Palácios, a partir da inoculação do tecido nervoso de camundongos neonatos. Reafirmando sua característica de aliar P\&D e produçãa, o IBPT - com níveis crescentes de milhões de doses de produção dessa vacina $^{6}$ - passou a ser o fornecedor exclusivo para as campanhas de erradicação da raiva levadas a cabo pelo governo federal, cujo sucesso se revelou incontestável: os casos de raiva tornaram-se eventos raros no Brasil.

5 Em 1957, foi organizado o Curso de Fisiologia de Microorganismos, "de grande importância para o desenvolvimento da bioquímica de microorganismos. Em regime de tempo integral, sempre no verão, o curso seria repetido por mais treze anos", contando com alunos de diversos Estados do Brasil. A área de bioquímica do IBPT manteve "longas relações de cooperação e simbiose" com a Universidade Federal do Paraná (BRAND; ROCHA, 1991, p. 71-72).

6 Entre 1970 e 1980, a participação dos segmentos metal-mecânica, material elétrico e de telecomunicações e material de transportes da indústria paranaense na indústria brasileira aumentou de 2,4\% para 5,5\%. Em 1985, esse percentual alcançou 9,9\%. 
Nessa mesma linha de atuação, em 1983, o IBPT deu início à linha de produção da vacina antirrábica humana, voltada também para atender às demandas do Ministério da Saúde. Desde então, a produção de vacinas antirrábica, pela expressividade sua escala e requisitos técnicos e operacionais de produção, além do aporte de volume muito expressivo de receitas, ainda marca as atividades do Instituto.

No entanto, pode-se afirmar que um terceiro momento crítico da trajetória do Tecpar torna-se evidente a partir do início dos anos 1980. Como decorrência de diversas iniciativas que se aceleraram desde meados da década de 1970, em 1983 foi criado, no âmbito do Instituto, o Centro de Tecnologia Industrial BrasilJapão, voltado para a prestação de serviços tecnológicos às indústrias. Esse Centro foi instalado em um novo campus do Instituto, localizado na Cidade Industrial de Curitiba, instalada na região oeste da capital paranaense, a $10 \mathrm{~km}$ do centro, já na vizinhança da Cidade Industrial de Araucária.

A instalação do Centro de Tecnologia Industrial Brasil-Japão respondeu a vários movimentos observados, no Paraná, na década de 1970:

- expansão da indústria paranaense no bojo do processo de relativa desconcentração espacial da economia brasileira, a partir do Estado de São Paulo e impulsionada, em particular, pelas estratégias definidas no II Plano Nacional de Desenvolvimento Econômico (1974-1978). Um dos marcos dessa expansão foi a construção da Refinaria Presidente Getúlio Vargas (Repar), inaugurada no final de 1976, na Cidade Industrial de Araucária, vizinha à CIC. Além disso, vinculada e anexa a essa Refinaria, em 1982, entrou em operação a Ultrafertil, votada para a produção de fertilizantes, cuja demanda encontrava-se em expansão em decorrência do crescimento e modernização da atividade agrícola, centrada na produção de soja e proteínas de origem animal (aves e suínos);

- criação da Cidade Industrial de Curitiba (CIC), em 1973. Com base em incentivos fiscais, físicos (serviços de demarcação de áreas e terraplanagem) e financeiros a partir das operaçôes do Banco de Desenvolvimento do Paraná, a CIC constituiu-se no espaço privilegiado do intenso avanço e diversificação da indústria estadual, em particular em segmentos da metal-mecânica e eletroeletrônico. ${ }^{7}$ Volvo (1977/1979), Bosch (1978), Furukawa (1977) e Siemmens (1974/1975) constituem exemplos de empreendimentos que se instalaram na CIC no decorrer dos anos 1990. A expansão industrial da década de 1970 introduziu no Estado a grande

7 Conforme o Estatuto do Tecpar. 
empresa moderna, com amplas escalas de produção e uso de tecnologias modernas, demandando serviços tecnológicos relativamente sofisticados (VASCONCELOS; CASTRO, 1999, p. 9);

- reorientação estratégica do IBPT por parte do governo do Estado. Em 1974, o Instituto, antes uma autarquia subordinada à Secretaria de Estado da Agricultura, passou a se vincular à Secretaria de Estado da Indústria e Comércio. Em 1978, foi criado o Instituto de Tecnologia do Paraná (Tecpar), que, como empresa pública, absorveu o IBPT, com base em uma nova orientação estratégica e tendo por diretriz "colaborar com o desenvolvimento científico e tecnológico dos setores privado e público, primordialmente no campo de aplicaçōes à indústria do Estado do Paraná". Os objetivos específicos colocados para o Tecpar foram: "proporcionar apoio tecnológico às atividades dos diversos setores econômicos do estado; criar ou adaptar tecnologias (...); promover a realização de estudos e projetos de natureza científica e tecnológica; formar e aperfeiçoar os recursos humanos necessários (...); e realizar intercâmbio com entidade nacionais, estrangeiras e internacionais na sua área de atuação". ${ }^{8}$ Além disso, o governo estadual, em 1972, criou o Instituto Agronômico do Paraná (Iapar), voltado para a pesquisa agropecuária, e, em 1977, estruturou a Empresa Paranaense de Assistência Técnica e Extensão Rural - Emater, que absorveu as atividades da Acarpa - Associação de Crédito e Assistência Rural, existente desde 1959. A modernização da atividade agropecuária e sua vinculação à jusante e a montante com o setor industrial implicaram o desenho de novas instituiçôes públicas que lhe viesse a dar suporte. $\mathrm{Na}$ área de estudos geológicos, prospecção e aproveitamento dos recursos minerais do Estado, o governo estadual criou, em 1977, a Mineropar (Serviço Geológico do Paraná). Assim, algumas das áreas de atividades do antigo IBPT passaram a ser objeto de ação de outras instituições públicas;

- avanços nas relações de cooperação entre o Paraná e a Província de Hyogo, no Japão, que resultou no apoio à construção do Centro de Tecnologia Industrial Brasil-Japão (CTI), iniciada em 1981. O início das tratativas formais dessa cooperação ocorreu em 1977, quando o governador do Paraná, Jayme Canet Junior, recebeu da Prefeitura de Hyogo correspondência solicitando formalização da proposta de criação do "Centro de Desenvol-

8 Ver, anexa, cópia do ofício encaminhado pelo governador da Província de Hyogo, Tokitada Sakai, ao governador do Paraná, Jayme Canet Júnior, em 17/08/1977. 
vimento Industrial do Paraná", 9 posteriormente denominado de CTI. Esse Centro estaria voltado para o fornecimento de informaçōes tecnológicas para a indústria estadual; orientação e treinamento de recursos humanos; e estudos e desenvolvimento de serviços tecnológicos. Na concretização do CTI, o apoio japonês foi não somente técnico, a partir do Instituto de Pesquisas Tecnológicas de Hyogo (especialistas visitantes, formação de recursos humanos, etc.), mas também financeiro e em espécie (material bibliográfico e equipamentos) por parte do governo japonês, por meio da Japan International Cooperation Agency - Jica. Além de recursos do orçamento do Estado, a instalação do CTI, inaugurado em 1983, contou com o aporte de recursos da Finep, por intermédio do Badep como seu agente financeiro. Estima-se que somente os dispêndios realizados pelo Tecpar com a construção e instalação esse Centro somaram cerca de US\$ 6 milhōes, no período 1980-1984, a preços de 2010, valores até hoje ainda relativamente expressivos para empreendimentos dessa natureza.

Pode-se afirmar que a cooperação técnica com instituições japonesas foi importante, na medida em que, formalizada, catalisou esforços e recursos orçamentários que viabilizaram a criaçáo do Centro de Tecnologia Industrial. No que se refere ao aporte técnico, é importante lembrar que, no final dos anos 1970, o Japão constituía uma das principais referências mundiais em serviços tecnológicos voltados para o setor industrial.

Desde então, articulando P\&D e produção, as atividades do Tecpar voltadas para o setor industrial se diversificaram, várias das quais apresentando escalas que podem ser consideradas expressivas a nível nacional. Nessa área, as suas principais atividades são:

- análises e ensaios laboratoriais para diferentes tipos de produtos (alimentos e bebidas; fertilizantes e calcários; madeira; medicamentos e produtos hospitalares; meio ambiente; metal-mecânica; papel e papelão; plásticos e borrachas; saneantes e domissanitários; produtos químicos; têxteis; tintas; e agroindústria);

- serviços de metrologia de diferentes tipos (dimensional; força; pressão; massa; eletricidade; tempo e frequência; temperatura; condutividade e $\mathrm{pH}$; e volume);

- certificação de sistemas (gestão da qualidade; gestão ambiental; gestão de saúde e segurança ocupacional; avaliação de segurança, saúde, meio ambiente

9 Conforme <http://www. fiocruz.br/cgi/cgilua.exe/sys/start.htm?infoid=4495\&sid=10>. 
e qualidade; e manejo florestal) e produtos (elétricos, telecomunicações; orgânicos; produção integrada de frutas; soja não OGM; cestas de alimentos; cachaça; cadeia de custódia; sacos de papel; e unidades armazenadoras);

- química fina (desenvolvimento e produção de padrões analíticos fitoquímicos de referência);

- inteligência artificial aplicada a processos industriais;

- desenvolvimento, análises e teste de motores com biodiesel;

- inspeção veicular;

- extensão e informações tecnológicas;

- Incubadora Tecnológica de Curitiba (Intec).

Indo além dessas atividades, em meados da década atual, a trajetória do Tecpar passou um por um quarto momento crítico, referente ao deslanche das ações que estão viabilizando um avanço do Instituto na área de biotecnologia ( $\mathrm{P} \& \mathrm{D}$ e produtos), em parceria com a Fundação Oswaldo Cruz, iniciada quando da criação do Instituto de Biologia Molecular do Paraná (IBMP), em 1999. ${ }^{10} \mathrm{O}$ desenvolvimento dessa parceria resultou na criação, em 2009, da unidade sul dessa Fundação, no campus do Tecpar da CIC, denominada Instituto Carlos Chagas (ICC). Nas suas atividades de P\&D, esse Instituto e o Tecpar, em parceria com a Empresa Brasileira de Hemoderivados e Biotecnologia (Hemobras) e com o apoio do Ministério da Saúde, estão implantando uma linha de produção de testes NAT, que utilizam técnicas de biologia molecular para detectar os vírus HIV e da Hepatite C (HCV) em doadores de sangue. Esta técnica permite um diagnóstico muito mais precoce destas infecçôes do que os métodos clássicos, tais como os testes Elisa, diminuindo, assim, o chamado período de "janela imunológica" e reduzindo o número de infecções ocasionadas por transfusões sanguíneas ou pelo uso de hemoderivados.

Como pode ser observada, a trajetória do Tecpar revela a capacidade da instituição em avançar e renovar seus rumos de forma a responder às demandas impostas pelas transformações em curso na economia e na sociedade brasileira, em geral, e na paranaense, em particular.

$\mathrm{O}$ destaque dado à cooperação com instituições japonesas pretende realçar um dos momentos críticos dessa trajetória, que, ao fortalecer suas açōes na área de serviços tecnológicos à indústria, criou também condiçôes favoráveis para o avanço das áreas de produção de imunobiológicos e produtos biotecnológicos, em particular no que se refere à disseminação interna de padrōes de garantia de qualidade.

10 Conforme Hemobras: <http://www.hemobras.gov.br/site/conteudo/pesquisa_curso.asp>. 
O Tecpar e o Centro de Tecnologia Industrial Brasil-Japão

\section{Referências bibliográficas}

BRAND, J. ROCHA, R. C. Z. Notas para a história de uma vanguarda cientifica 19411991: do IBPT de Marcos Augusto Enrietti ao Tecpar. Curitiba: Cidadão e Campo, 1991.

LUNARDI, M. E. Organização da Ciência no Paraná: a contribuição do IBPT. Curitiba: Banestado, 1993.

MEARTINS, C. M. Processamento de imagens históricas do Instituto de Tecnologia do Paraná. Monografia apresentada à disciplina Metodologia de Pesquisa em Informação II, do Curso de Gestão da Informação do Setor de Ciências Aplicadas da Universidade Federal do Paraná, 2006.

PADIS; P. C. Formação de uma economia periférica: o caso do Paraná. Curitiba: Ipardes, 2006.

VASCONCELOS, J. R.; CASTRO, D. Paraná: economia, finanças públicas e investimentos nos anos 90. Brasília: Ipea, 1999 (Texto para discussão, n. 624). 
Toltitinda Sakai Coverandor

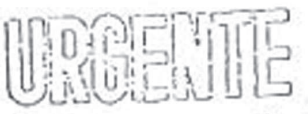

17 de agosco de 1977

\section{Ao 1loaçável}

Jaine Canct Junior

Javernador do Escrulo do Parsna

palácio 1 guasu

Curitiba - Рэгғав Bras: 1
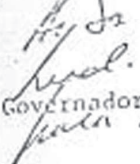

l.

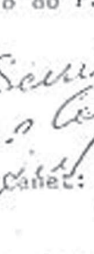

Fines to

zifitario

\section{i. $/ 1017^{2}$}

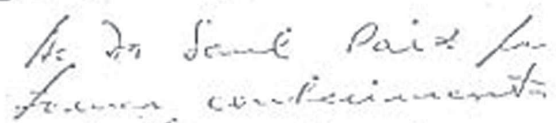
Projeto de Cooperaçao Tecpe do Japao, referente a criaça do centro de Desenvolvimento Industra do ratam, cáo pela Sr. Yoshiliazólohisa, nosso representente oficanl no kstado do Paraná.

Nosso governo da prefeitura e a Áência de Cooperação Internacional do Japao, órg̈̃o execucivo principal para o pro jeto, estão aguardando ansiosamente que a proposia do Projeto seja for malmente submetida ao Governo Jepoaés pelo Governo Federal do Brasil. Te malmos que un atrazo naior possa presenter w passo atrâs no tranquilo começo deste projeto.

Tendo er vista que as rêlaçōes de arsizade tor nam-se cada vez mais estreitas entre seu Estado c nossa prefcitura ao can po económico e cm outros canpos e tarbém o notável prozitesso da cídade Industrial de Cutitiba, estamos nuito inceressacios no futuro desenvolvi mento de seu Estado através da cooperaçäo entre as partes intercssadas de arbos os lados. Gostaríamos nuitíssimo, portanto, que V.excia. exani nasse a Proposta de Projeto acina pencionada e toasase as providêncies necessárias para que o projeto seja adotado como neio de cooperaçāo téç nica entre o Japão e o Brasil o mais brevesente passível.

Ficaríanos felicíssimos ca prestar esclareci mentos caso hajan perguntas a respeito do tamanho do projeto, detalíes do plano, problemas financeiros, ou quaisquer outros particulares sobre os quais V.Excia. possa achat conveniente consultar-nos antecipodanente.Por gentileza, transmita-nos essas düvidas a qualquet hora.

Espero que esta nossa solicitaçăo meтeçavor: pronta atençöo e peranecemos, coin os mais calorosos votos quanto à vó sa felicidade e contínua prosperioade do seu Estado.

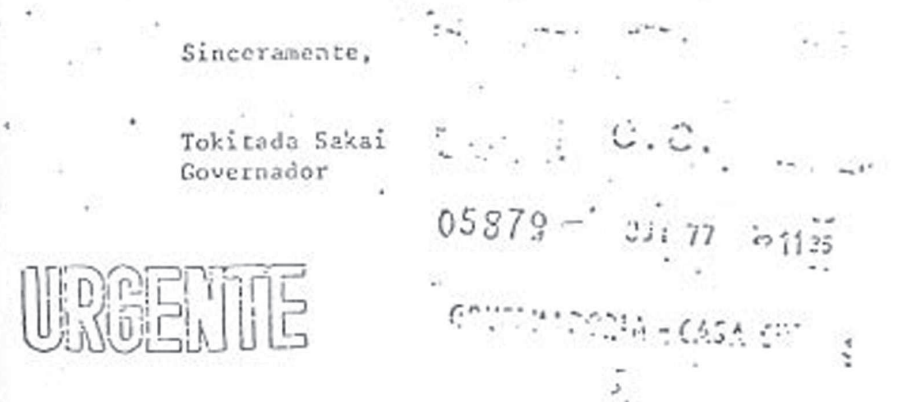

